\title{
PORE WATER PRESSURE MEASUREMENTS IN THE INTERPRETATION OF THE HYDRAULIC BEHAVIOUR OF TWO EARTH DAMS
}

\author{
Luca Pagano ${ }^{\text {i) }}$, Enzo Fontanella ${ }^{\text {ii) }}$, Stefania Sica ${ }^{\text {iii) }}$ and Augusto Desideri ${ }^{\text {iv) }}$
}

\begin{abstract}
The paper describes and interprets watertightness problems that occurred in two Italian earth dams: the Polverina Dam, a zoned earth dam with vertical clay core, and the Zoccolo Dam, a homogeneous embankment with upstream facing of bituminous conglomerate. Measurements of seepage flows, pore water pressures and displacements in different stages of the dams' lifetime were collected and suitably interpreted to detect the effectiveness of measured physical quantities in revealing watertightness problems. The paper focuses on the role of pore water pressure measurements to such a scope and enhances how the effectiveness of such measurements may be strongly affected by the particular stage reached by the consolidation process within the dam. The analysis of the two case-studies proved that pore water pressure measurements may result effective in revealing hydraulic problems only when significant re-equilibrium processes have taken place in the dam zones where the measurement points are located. Measurements result, instead, ineffective during a nearly undrained stage. The paper also discusses the effectiveness of seepage flow measurements to detect possible hydraulic problems.
\end{abstract}

Key words: case history, dam, measurement, pore pressure, seepage (IGC: H4/E7)

\section{INTRODUCTION}

Geotechnical problems which earth dams could experience during their operational stages are mainly related to slope instability and internal erosion phenomena. Updating dam safety and efficiency with regard to such concerns is becoming a crucial matter, especially for those structures that have been in operation for several decades. To accomplish this task, dam loading history should be preventively known; in addition, monitored physical quantities and results from periodical inspections should be suitably collected and interpreted during the different stages of the dam's life.

Time typically provides beneficial effects to the mechanical properties of dam and foundation soils (Martin, 1993) because of soil strengthening due to creep and bounding phenomena. According to Charles (1997) and Jappelli (2003), time, in general, reduces global instability risks but may enhance internal erosion. Piping and suffusion processes may expand over time in the embankment, foundation soils or along the contact between the embankment and a conduit spillway, drain or other appurtenance. Large seepage forces may cause new fractures, widen existing ones and produce concentrated leaks with erosion of soil particles along the walls of the cracks. When not prevented by appropriately designed filters, such mechanisms may increase leakages and progressively reduce hydraulic efficiency or safety of the dam. Problems caused by internal erosion years after the first filling are not unlikely (e.g., Gould and Lacy, 1993; Torbla and Rikartsen, 1997; Johansen and Eikevik, 1997; Riemer et al., 1997).

For old dams periodical inspections and continuous monitoring activity (typically involving displacements, strains, stresses, pore water pressures, seepage flows, content of soil particles in seepage flows) should, therefore, be aimed at identifying existing cracks and erosion processes, or simply at detecting state conditions potentially able to generate such phenomena. Periodical inspections may support the task of identifying anomalous seepage. If a seepage flow emerges somewhere on the downstream face of the dam, indicators of such phenomenon may be, for example, a "soft" and wet area with significant amount of greenery, or a flowing "spring".

Seepage flow measurements which arise inconsistent with the impounding level evolution may often be related to a progressive reduction of the dam water tightness. Measurement of soil particle content in water seeping downstream is a further important indicator of dam hydraulic problems because turbid water often is what

i) Assistant Professor, PhD, Dipartimento di Ingegneria Idraulica, Geotecnica e Ambientale, Università degli Studi di Napoli, Italy (lupagano@ unina.it).

ii) Researcher Assistant Professor, PhD, Dipartimento di Ingegneria Strutturale e Geotecnica, Università di Roma La Sapienza, Italy.

iii) Assitant Professor, PhD, Dipartimento di Ingegneria, Università degli Studi del Sannio, Italy.

iv) Professor, PhD, Dipartimento di Ingegneria Strutturale e Geotecnica, Università di Roma La Sapienza, Italy.

The manuscript for this paper was received for review on November 14, 2008; approved on December 2, 2009.

Written discussions on this paper should be submitted before November 1, 2010 to the Japanese Geotechnical Society, 4-38-2, Sengoku, Bunkyo-ku, Tokyo 112-0011, Japan. Upon request the closing date may be extended one month. 
reveals erosion problems occurring in the soils intercepted by the flow paths.

Even a suitable interpretation of the pore water pressures measured within the dam body and foundation soils may yield information about changes in dam hydraulic properties, including those changes related to cracks and erosion problems.

Distribution and evolution of other monitored quantities, such as displacements, strains and total stresses, aid to characterize the overall dam behaviour (e.g., Pagano et al., 1998; Pagano et al., 2001; Sica et al., 2008) and detect state conditions often associated to crack formation, or to diagnose hydraulic problems brought to the fore by seepage flows or pore water pressures. When much lower than overburden pressures, vertical total stresses measured in the core of a zoned earth dam indicate core arching and state conditions supposed to enhance crack formation and propagation during the impounding stages (e.g., Sherard, 1986; Talbot and Deal, 1993; Dounias et al., 1996). Settlement or strain producing significant distortion in the watertightness element may indicate cracks of that element and consequent leakage.

A given measured quantity is more or less effective in supporting the characterization of the hydraulic behaviour of dams depending on its intrinsic meaning, reliability and representativeness, as well as on the model used for measurement interpretation (Pagano et al., 2006).

Two Italian case histories suffering watertightness problems during their lifetime are described in the paper focusing on the capability of different measured quanti- ties in revealing the hydraulic behaviour of these structures. Watertightness problems are firstly brought to light through seepage flow measurements. Subsequently, the same problems are reviewed by interpreting settlement and pore water pressure measurements, in order to understand the effectiveness of such physical quantities in indicating hydraulic problems and working as safety indicators.

The paper preliminarily presents the two case histories in their typologies, geometries, soil properties and monitoring systems. Following, the seepage flow measurements of the two dams are illustrated and interpreted. The analysis of such cases is finally supported by pore water pressure measurements. Some points of the interpretation process are synthesized and generalized in the conclusion section, trying to define the roles of different measurements in detecting dam hydraulic problems.

\section{CASE-HISTORIES}

\section{Zoccolo Dam}

Built for hydroelectric power generation between March 1964 and November 1965 in Northern Italy, the Zoccolo Dam has a maximum height of $66.50 \mathrm{~m}$. It is a homogeneous earth fill (Fig. 1) made of gravelly silty sand, compacted at the optimum of the modified Proctor, and with the upstream side protected by a facing of bituminous conglomerate. The compacted gravelly silty sand has a maximum particle size equal to $400 \mathrm{~mm}$, with percentages of sand and silt equal to $15 \%$ and $10 \%$, re-
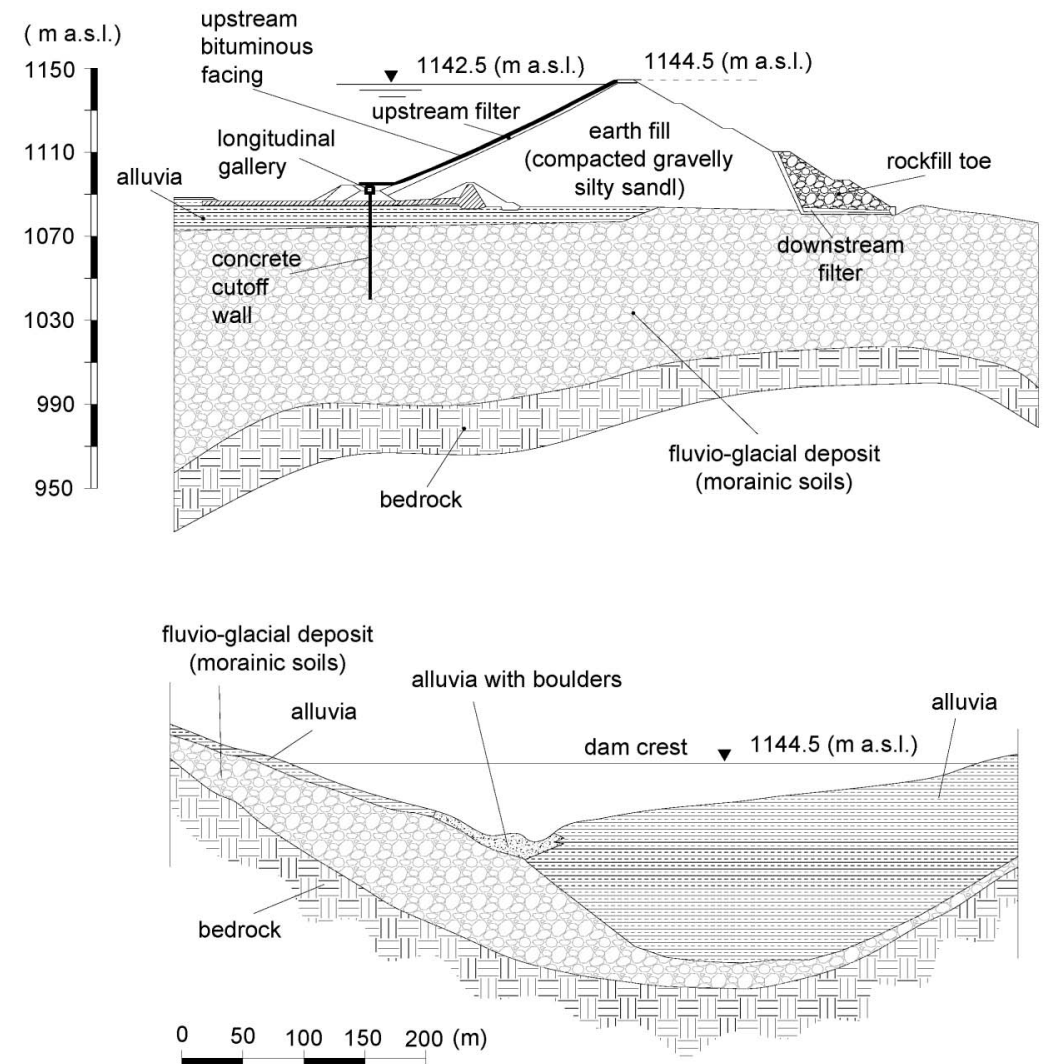

(b)

Fig. 1. Zoccolo Dam: (a) main cross section and (b) longitudinal section at the dam crest 
spectively. Permeability tests indicate that the permeability coefficient is around $10^{-5} \mathrm{~cm} / \mathrm{s}$.

The upstream watertight facing consists of $8 \mathrm{~cm}$-thick binder on which three watertight layers, with thickness between 4 and $5 \mathrm{~cm}$, are superposed; each layer is formed by highly impervious bituminous conglomerates and joined to the other layers by a bitumen emulsion. The watertight facing rests on carefully-placed filter-material layer that is $3 \mathrm{~m}$ thick at the crest and thicker downward. The filter is aimed at avoiding that during a rapid drawdown significant pore water pressures under the facing, not equilibrated by the reservoir pressure, could damage the facing itself. The watertight facing is extended down to the top of the foundation concrete cut-off wall.

The embankment is built on fluvio-glacial soils, i.e., alluvials and conoids, which essentially are gravels and sands with some boulders. The permeability coefficient of the foundation soils, measured by variable head tests conducted at different boreholes, is around $10^{-3}-10^{-2}$ $\mathrm{cm} / \mathrm{s}$ in the superficial alluvia and around $10^{-4}-10^{-5} \mathrm{~cm} / \mathrm{s}$ in the morainic soils. Since the impervious bedrock lies in depth down to a maximum of $100 \mathrm{~m}$ below the ground level, watertightness of the foundation soils is ensured by means of a diaphragm sunk into the foundation for about $50 \mathrm{~m}$. The diaphragm is made of interlocked concrete piles having diameter equal to $0.55 \mathrm{~m}$ and forming a continuous structure. The purpose of the diaphragm is not to prevent seepage through the subsoil but to increase the seepage path, in order to reduce the hydraulic gradients and, consequentially, the seepage flow rates.

At the level of the embankment base two galleries cross longitudinally and transversally the dam body (Fig. 2). The longitudinal gallery is placed at the top of the cut-off wall (Fig. 1(a)). The transversal one runs from the upstream to the downstream boundary of the dam in correspondence to the middle zone of the embankment (Fig. 2(a) and (c)).

The dam has been instrumented to measure seepage flows, pore water pressures (in the embankment and the foundation soils) and displacements. Seepage flows are measured through a weir built on the downstream side of the dam (Fig. 2(a)) at the exit of the transversal gallery. The weir collects water drained by two filter systems placed within the dam (Fig. 1(a)): the upstream filter, located under the watertight facing (water is intercepted by tubes along the dam transversal gallery up to the wear), and the downstream filter, located downstream and separating the rockfill toe from the dam body and the foundation. Measured seepage flows are mostly those seeping through the dam body and the shallow foundation soils.

To measure pore water pressures many instruments have been installed in the dam. In what follows, only instruments and measurements functional to the scope of the work will be considered. The measurement points that will be considered in characterizing the hydraulic behaviour of dam are placed at the bottom of the transversal gallery (Figs. 2(a) and (c)), in correspondence to section 13 (Figs. 2(a) and (b)) and downstream, close to the
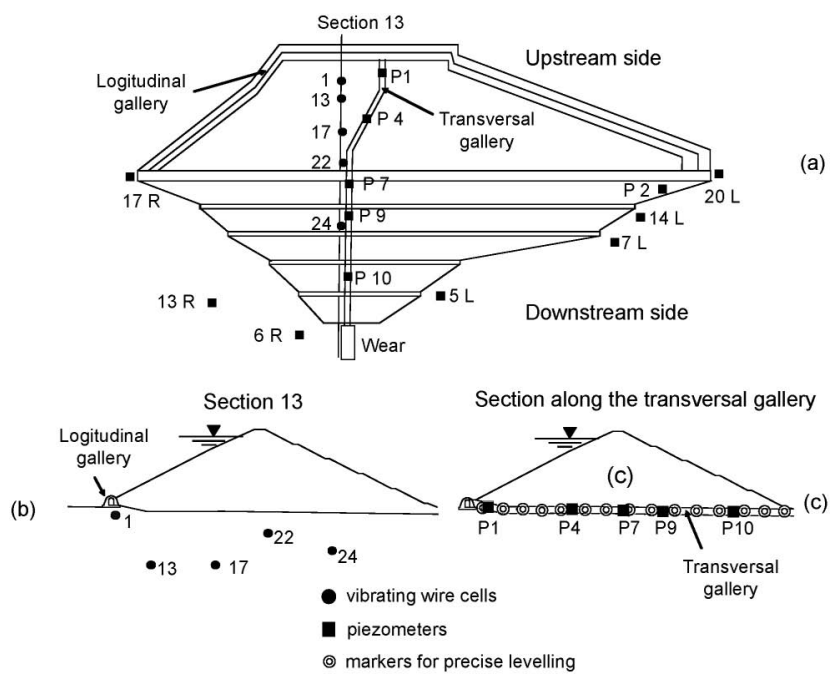

Fig. 2. Location of the instruments to measure pore water pressures and seepage flows in the Zoccolo Dam: (a) dam plant, (b) cross section 13 and (c) cross section at the transversal gallery

right and left banks of the valley (Fig. 2(a)). Vibrating wire cells (circles in Fig. 2) and piezometers (squares in Fig. 2) have been installed within the foundation soils. Open tube piezometers are equipped with a pressure transducer, placed below the minimum level presumed for the water surface at the measurement point. Precise levelling of the targets (double hollow circles in Fig. 2(c)) placed within the transversal gallery provides the transversal deformed shape of the foundation plane around the middle zone of the dam.

\section{Polverina Dam}

The Polverina Dam is a zoned earth dam $27.5 \mathrm{~m}$ high, built in central Italy between March 1964 and November 1965. The dam's cross section and plant are shown in Fig. 3. The core (Fig. 3(a)) is comprised of clayey sandy silt (Plasticity Index PI = 12-18\%) compacted around the optimum of the Standard Proctor Test. The permeability coefficient is less than $10^{-8} \mathrm{~cm} / \mathrm{s}$. The downstream shell is made of sandy silty gravel with permeability coefficient around $10^{-5} \mathrm{~cm} / \mathrm{s}$. Sandy gravel forms the upstream outer shell, characterized by permeability coefficient around $10^{-3} \mathrm{~cm} / \mathrm{s}$.

Around the centre of the valley, the foundation soils consist of a 20-meter deep fluvial deposit which lies on a marly bedrock (Fig. 3(b)). A lacustrine clayey silt deposit (Plasticity Index $\mathrm{PI}=20-26 \%$; permeability $k \cong 10^{-8}$ $\mathrm{cm} / \mathrm{s}$; compressibility index $C_{\mathrm{c}}=0.17-0.26$ ) is included within the sandy gravel layer (Figs. 3(a) and (b)). It is around $8 \mathrm{~m}$ thick at the valley centre, but then it thins out and disappears towards the two abutments (Fig. 3(b)). A half-meter thick cut-off wall made of concrete panels provides watertightness inside the foundation soils. The wall goes from the core to the marls. It penetrates 3 meters inside the core and 2 meters inside the marls. The dam does not have any inspection gallery crossing the embankment. Also the Polverina Dam has been instrumented to measure seepage flows, pore water pressures and displace- 


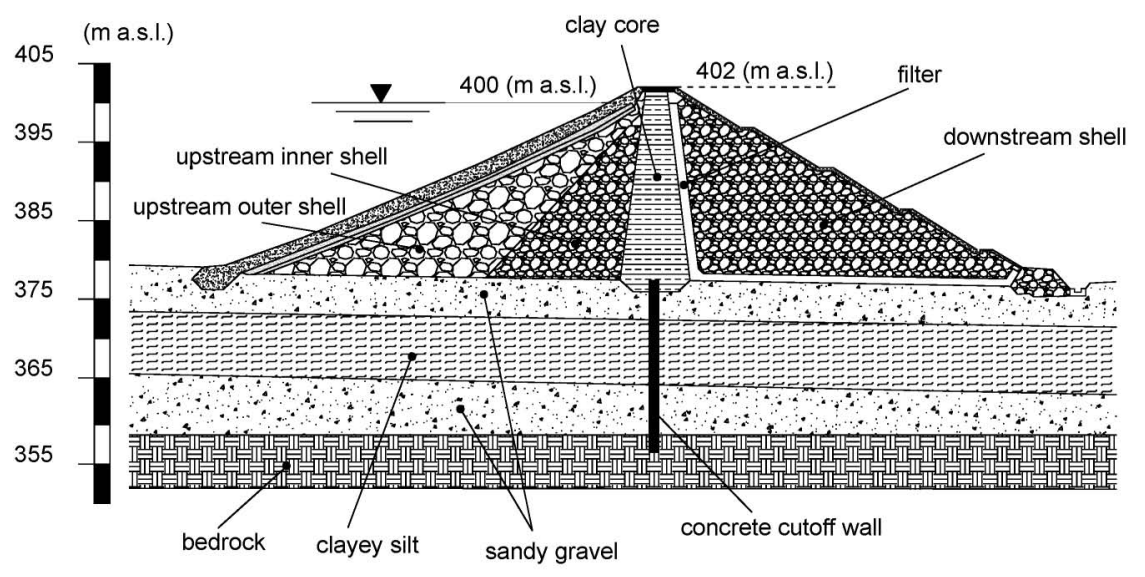

(a)

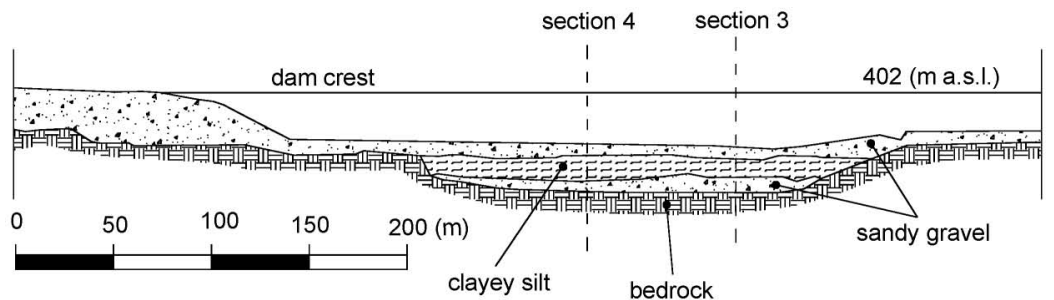

(b)

Fig. 3. Polverina Dam: (a) main cross section and (b) longitudinal section at the dam crest

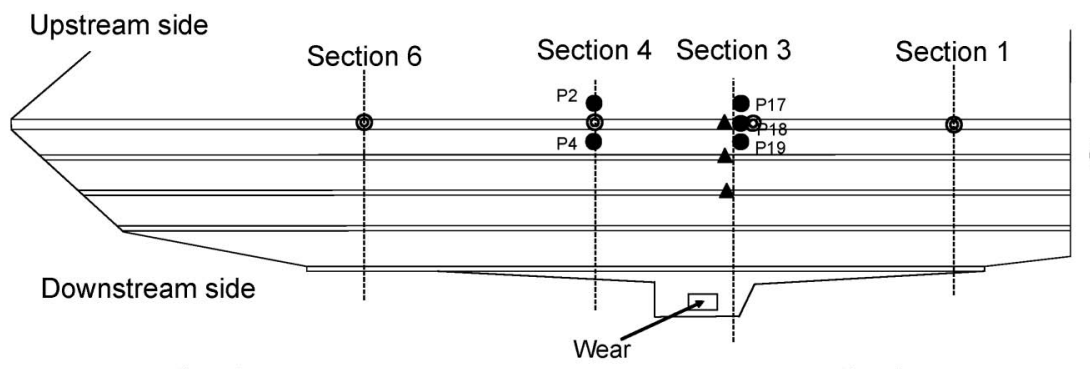

(b)

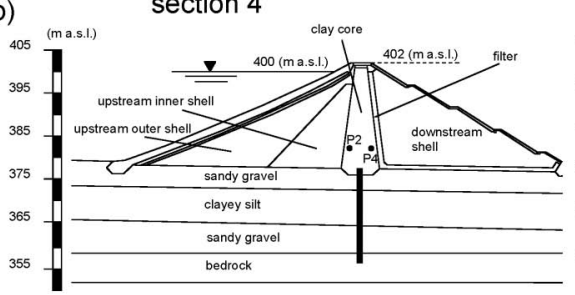

section 3

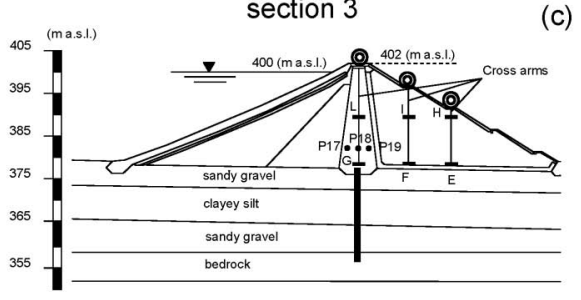

(c)

(a)

- vibrating wire piezometers installed within the embankment

$\Delta$ cross arms

๑ targets for precise levelling

Fig. 4. Location of the instruments to measure pore water pressures, seepage flows and settlements in the Polverina Dam: (a) dam plant, (b) cross section 4 and (c) cross section 3

ments (Fig. 4).

Seepage flows are measured through a weir placed downstream (Fig. 4(a)). It collects water draining from the filter that separates the downstream shell from the clay core and horizontally from the sandy gravel (Fig. 3(a)). Also in this case water collected by the filter system is mostly seeping through the dam body and the shallow foundation soils.
To measure pore water pressures in the dam core, during the construction stage vibrating wire piezometers were installed at the two cross sections 3 and 4, shown in Fig. 4(a). Piezometer locations for sections 4 and 3 have been shown in Figs. 4(b) and (c), respectively. Measurement points are located just 2 meters above the top of the cut-off wall. Finally, to characterise the dam displacement field, targets for precise levelling (Figs. 4(a) and (c)) 


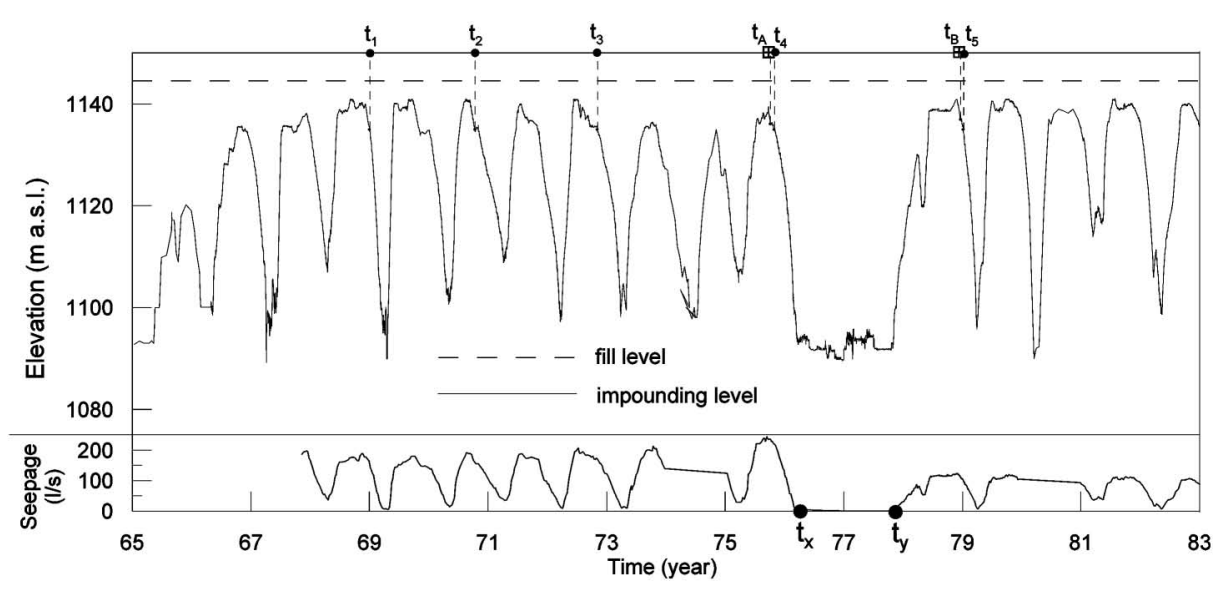

Fig. 5. Zoccolo Dam: impounding levels and seepage flows measured during the first two decades of the dam lifetime

and cross arms (Fig. 4(c)) were installed along the dam surface and within the embankment, respectively.

\section{SEEPAGE FLOW MEASUREMENTS}

For the Zoccolo Dam, Fig. 5 shows the evolution of the impounding level along with time histories of seepage flows. The impounding level is forced to oscillate significantly, due to the use of the reservoir to generate hydroelectric power. During the first years of operation (November 1965-March 1976) the maximum impounding level oscillates up to a nearly constant maximum value and seepage flows oscillate consistently with the impounding level. The significant amount of the seepage (more than 150 litres/sec) until 1972 in itself indicates poor efficiency of the dam in storing water. Starting from 1972 the maximum values of seepage tend to rise up to 200 litres/sec, indicating a progressive loss of watertightness. This represents a safety concern other than an efficiency problem.

During the period April 1976-October 1977 (time period from $t_{\mathrm{x}}$ to $t_{\mathrm{y}}$ in Fig. 5) the impounding level was lowered and grouting was performed on the upstream side of the cut off wall.Grouting was performed along two different lines of boreholes, carried out $1 \mathrm{~m}$ apart each other in the direction parallel to the longitudinal gallery. Boreholes were all characterized by a diameter equal to 8 $\mathrm{mm}$. They were carried out in such a way that those of the interior line (i.e., closer to the gallery) were offset with respect to those of the exterior line. The boreholes of the exterior line are $28 \mathrm{~m}$ deep while those of the interior line $18 \mathrm{~m}$. The grout material, inserted by tubes with rubber valves at every $30 \mathrm{~cm}$, was a mixture made of $26.6 \%$ in concrete, $6.6 \%$ in bentonite and $66.8 \%$ in water. The amount of mixture grouted from each valve ranged between $0.12 \mathrm{~m}^{3}$ and $0.24 \mathrm{~m}^{3}$, depending on the maximum pressure fixed at the valve itself.

When the water table rose again in 1977 to the same maximum values previously reached, the maximum seepage flows were around 100 litres/sec, i.e., just half the previous maximum value. Values remained quite stable in time, demonstrating the effectiveness of the mitigating works.

For the Polverina Dam, Fig. 6 shows the time histories of impounding levels during the first three years of operation, along with time histories of seepage flows. During the first step of the trial fills monitored seepage flows rapidly built up without any tendency to stabilize at a constant impounding level (Fig. 6, branch O-A). The poor amount of seepage (around 20 litres/sec the maximum value reached) did not bring about efficiency concerns but rather a safety concern due to the increasing trend that clearly indicated a progressive loss in watertightness. Trial fills were interrupted, the impounding level was lowered (Fig. 6, branch B-C) and activities were started in order to investigate the causes of the observed loss in the dam watertightness.

The contact between the core and the wall was grouted on the upstream side of the cut-off wall. Grouting was performed in boreholes parallel to the cut-off wall. The boreholes were carried out $1.5 \mathrm{~m}$ apart each other along the upstream shell, with an inclination alternatively equal to $5 \%$ and $15 \%$ with respect to the vertical axis. The material adopted for the grout was a mixture made of $4.6 \%$ in concrete, $0.85 \%$ in bentonite, $8.9 \%$ in silt and $85 \%$ in water. Grouting was made with pressures not exceeding $2 \mathrm{MPa}$. During the works the water level was raised up (Fig. 6, branch D-E) and a progressive reduction in seepage was observed at demonstrating the efficacy of the mitigation efforts.

\section{WATERTIGHTNESS PROBLEMS AND SETTLEMENT MEASUREMENTS}

Settlement measurements may provide some elements for the diagnosis of the watertightness problems illustrated in the previous section. For the Zoccolo Dam, settlements measured in the transversal gallery, close to the foundation plane, proved useful in diagnosing the problem (Fig. 7). They indicated that the foundation plane moved significantly over the entire construction stage and afterwards, during the operational stages. Upstream settlements arose higher than the downstream ones, due to a thicker deformable subsoil in the upper zone, also con- 


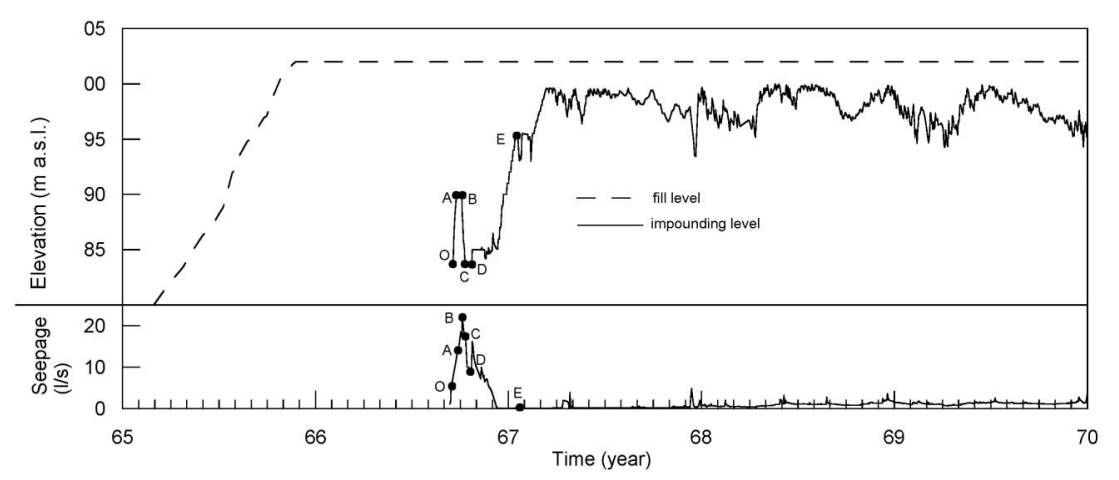

Fig. 6. Polverina Dam: impounding levels and seepage flows measured during the first three years of the dam lifetime
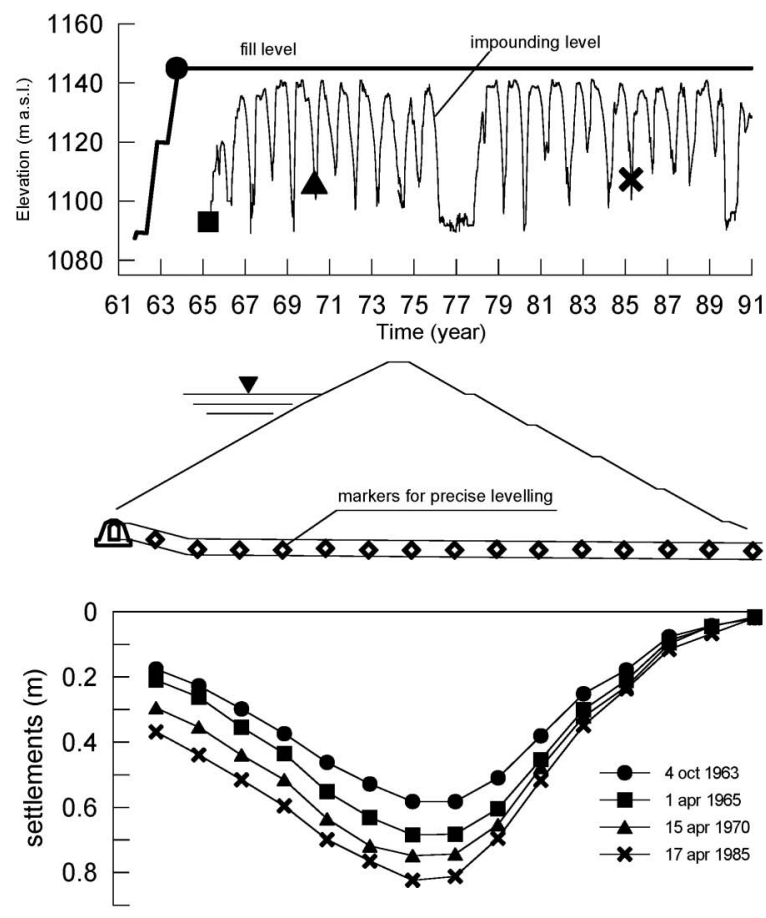

Fig. 7. Zoccolo Dam: isochrones of the settlements measured along the transversal gallery during the operational stages (for each isochron, the corresponding time has been marked in the upper plot with a symbol that is the same of the isochron curve in the lower plot)

taining small lenses of compressible silty-sands (see Fig. 1). The measured deformed shapes of the foundation plane suggested that during the operational stages a progressive and significant distortion of the cut off wall might have taken place, inducing progressive damages to it and, consequently, lack in dam watertightness. This interpretation, along with observations that will be provided in the following section led to relate the increasing leakages to a progressive lack in watertightness of the foundation piles.

For the Polverina Dam, settlement measurements indicated a clear deformation pattern of the dam. Precise levelling measurements carried out along the dam crest during the operational stages are plotted in Fig. 8 in terms of crest deformed shapes along the longitudinal axis at fixed time intervals. They clearly indicate that the

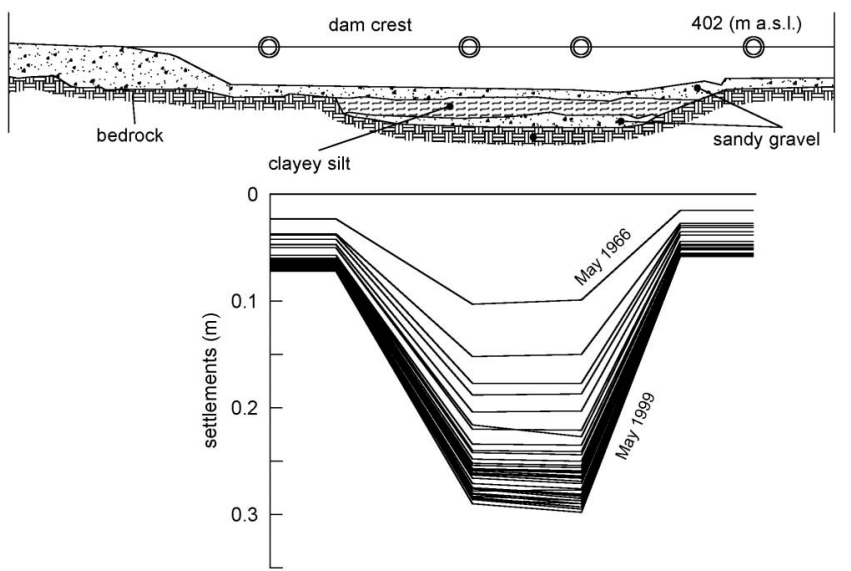

Fig. 8. Polverina Dam: yearly isochrones of the settlements measured along the dam crest during the operational stages (measurements are taken at the top of the cross-arms installed in the four monitored sections of the dam shown in Fig. 4)

dam settled significantly in the middle part, due to the presence of the compressible silty sand layer and that differential settlements were relevant in different dam zones.

The settlement curves which become progressively closer over time indicate that settlement derivative lowers due to consolidation phenomena. This statement may be further supported by representing settlement time-histories of points belonging to a central section of the dam, such as, for example, section 3 (Fig. 9). Since each measurement starts when the selected point is put in place during the construction process, the initial time delay of any single curve results as much higher as the elevation of the point at hand. During the impounding stages the differences in settlements between the base foundation and the crest are almost constant, thus indicating that settlements were essentially governed by the deformation of the foundation soils.

Settlements measured by the cross-arms installed at the section 3 (Fig. 10) indicate that from the beginning of the construction stage the foundation plane settles significantly due to the relevant consolidation strains experienced by the highly compressible clayey silt layer. Foundation settlements propagate everywhere within the 


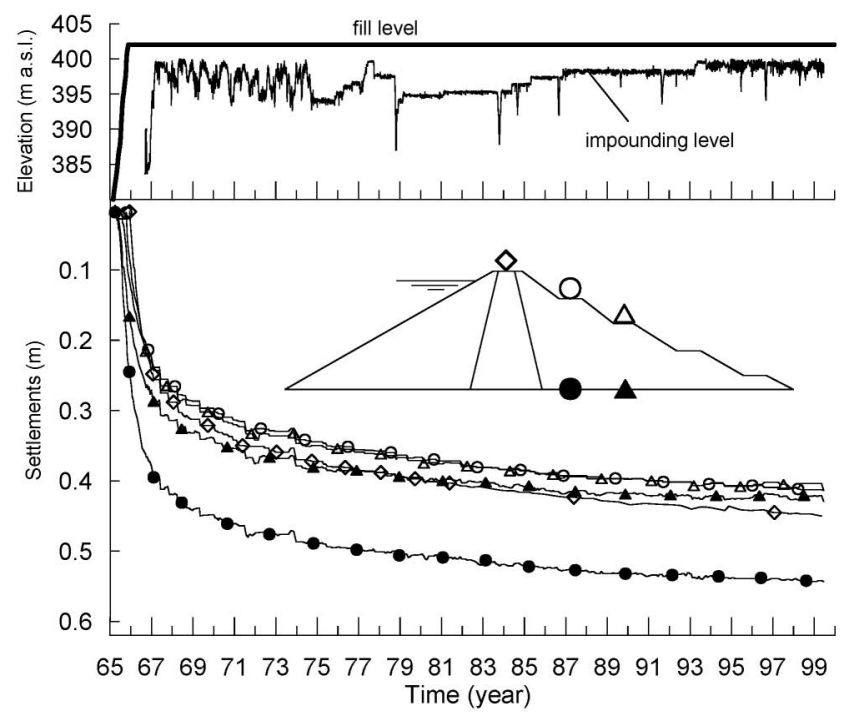

Fig. 9. Polverina Dam: settlement evolution during the construction and the impounding stages at different points of section 3 (each curve refers to the point indicated on the dam section with the same symbol of the curve)

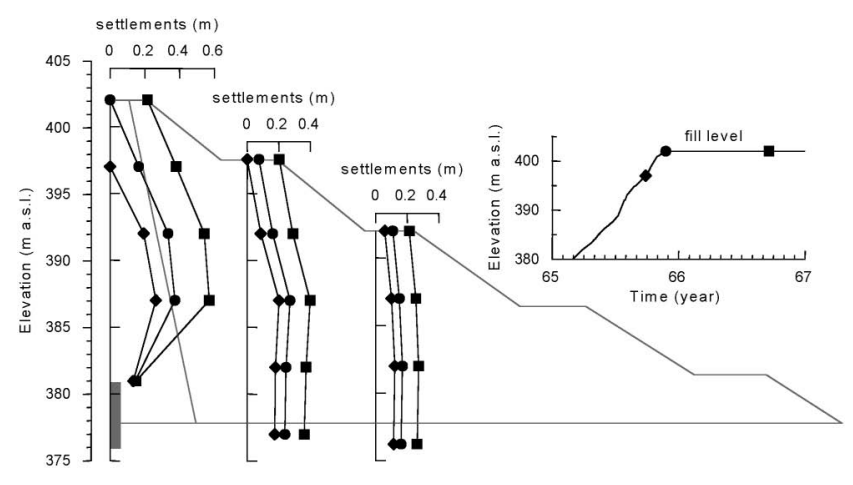

Fig. 10. Polverina Dam: settlement profiles measured during the construction stage at the three cross-arms installed in section 3

dam body, except around the cut-off wall. Here they are inhibited since the wall does not move, being made of much stiffer material than the surrounding soils and being founded on the bedrock. Significant differential settlements may, therefore, be assumed to occur between the thin core zone stopped by the wall and the wide zone following the foundation settlements.

For the same cross-arm measurements shown in Fig. 10, Fig. 11 plots the settlement profiles along two horizontal branches (indicated in Fig. 4(c)), one located at the embankment foundation level (Fig. 4(c), markers E-F-G) and another just above the embankment midheight (Fig. 4(c), markers H-I-L). Settlement values refer to the time just before the start of the trial fills, without including the settlements developed during the construction stages. Even during the impounding stages settlements are significant in the entire dam body but null around the cut-off wall. Deviatoric deformations and cracking may be consequently argued to take place within the core. The first impounding of the dam would have en-

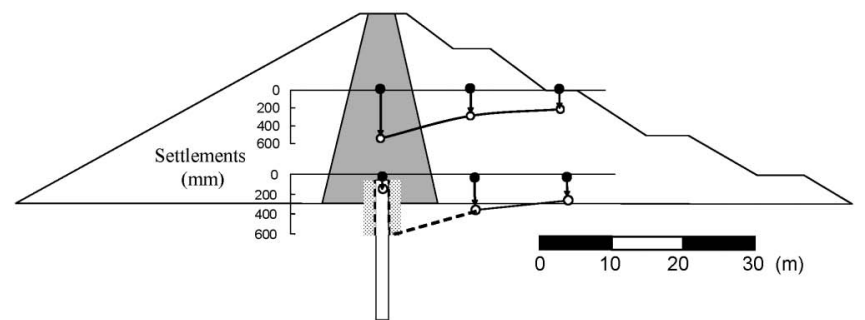

Fig. 11. Polverina Dam: settlements measured at two different elevations just before the start of the trial fills (settlements developed during the construction stages not included)

larged and propagated existing fractures, thus causing the watertightness problem.

\section{WATERTIGHTNESS PROBLEMS AND PORE WATER PRESSURE MEASUREMENTS}

In the previous sections two hydraulic problems were illustrated by comparing the evolution of seepage flow measurements with that of impounding levels and looking at settlement distribution and evolution. From now on the same cases are reviewed with the further support of piezometric head measurements. The scope is that of evaluating to what extent piezometric heads may indicate watertightness problems and work as safety indicators.

For the Zoccolo Dam, Fig. 12 adds to the evolution of the impounding levels and seepage flows already shown in Fig. 5, the evolution of the piezometric heads measured at the piezometers P1, P4, P7 and P9 located along the transversal gallery in correspondence to the dam base foundation. Piezometric heads all oscillate in phase with the impounding levels reproducing trends very similar to that of the seepage flow measurements. Sensitivity to changes of the impounding levels is more pronounced at points located upstream than at points located downstream, the former being closer to the boundary condition forced by the reservoir and the latter to the boundary conditions forced by the downstream groundwater. The ready response of piezometric head measurements to changes of impounding levels is due to the high permeability of both embankment and foundation soils. Drained conditions make the hydraulic behaviour of dam poorly influenced by static factors, so that changes in piezometric heads are regulated by changes in hydraulic boundary conditions or in hydraulic soil properties through a sequence of steady state conditions. Peak values of piezometric heads periodically reached at the points located upstream (Fig. 12, points P1 and P4) tend to progressively increase in the time period preceding the grouting works and to substantially lower after the works. The whole observed trend is quite similar to that previously shown and discussed for the seepage flow measurements.

If steady state conditions take place under constant boundary conditions, the piezometric heads at a given point can change only if the permeability distribution is changing within the seepage domain. A piezometric head 


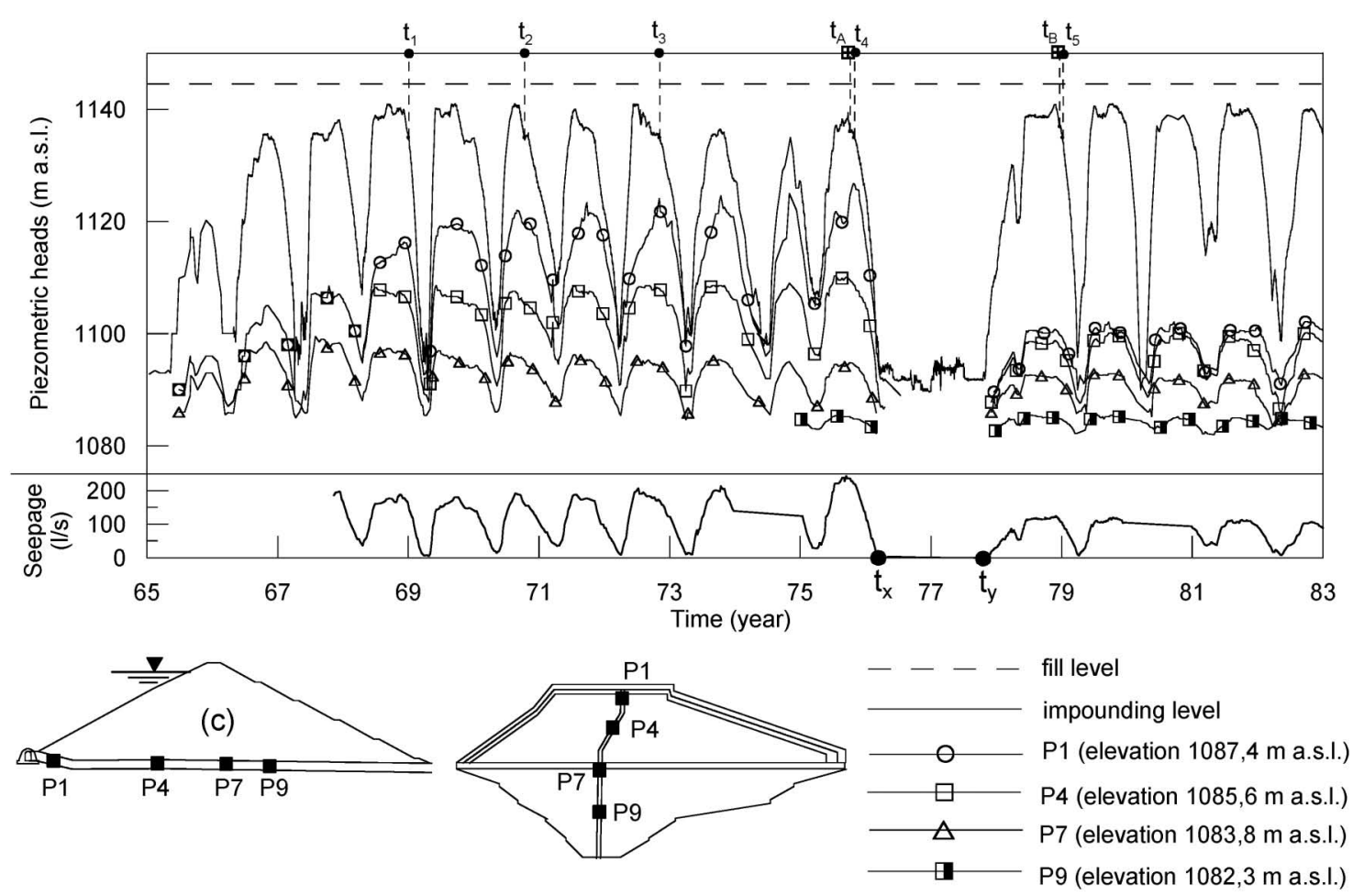

Fig. 12. Zoccolo Dam: impounding levels, piezometric heads in the transversal gallery and seepage flows measured during the first two decades of the dam lifetime

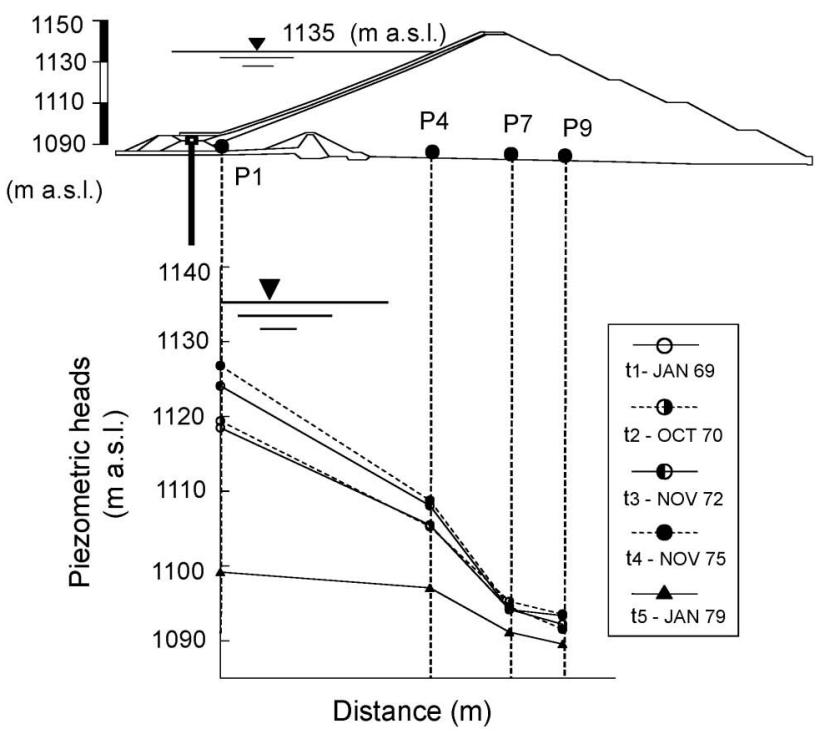

Fig. 13. Zoccolo Dam: distribution of piezometric heads measured in the transversal gallery at the different times indicated in Fig. 12

increase (decrease) occurs if the permeability of the zone located upstream of the point is increasing (decreasing) with respect to the permeability of the zone located downstream.

Figure 13 plots piezometric head distribution at the four control points P1, P4, P7 and P9 for the different times (from $t_{1}$ to $t_{5}$ ) marked in Fig. 12. The change with time in piezometric head distribution (Fig. 13, times $t_{1}, t_{2}$, $t_{3}, t_{4}$ ) clearly shows that the permeability in the upstream zone of the foundation soils increased with respect to permeability in the downstream zone before the grouting works, i.e., a progressive deficiency in watertightness of the cut off wall took place. Such deficiency did not change piezometric heads measured in the downstream zone because these latter are controlled by the groundwater boundary condition, whatever the permeability distribution. The effects induced by the subsequent works in terms of piezometric head distribution (Fig. 13, time $t_{5}$ ) arise consistent with the interpretation just above formulated. As a matter of fact, the watertightness of the cutoff wall enhanced by grouting reduced the permeability in the upstream zone, producing a significant decrease in piezometric heads measured close to the wall and leaving the downstream piezometric heads still unaltered.

Measurements taken at the section 13 (Fig. 14) indicate trends quite consistent with those associated to the measurement points located in the transversal gallery. At the upstream measurement points the peak values before the grouting works increased up to May 1971 and decreased significantly after works. Also in this case, the influence of the works was minimal in the downstream zone. Figure 15 represents measurements taken at the transversal gallery and at section 13 in terms of piezometric head contours for two different times, chosen just before and right after the grouting works (times $t_{\mathrm{A}}$ and $t_{\mathrm{B}}$ in Figs. 12 or 14). The plot evidences that grouting modifies the hydraulic behaviour of dam moving the piezometric head contours upstream.

Measurements taken in the foundation soils close to the left bank of the valley (Fig. 16) result affected by the works while measurements taken close to the right bank (Fig. 17) show insensitivity to the works, meaning that 


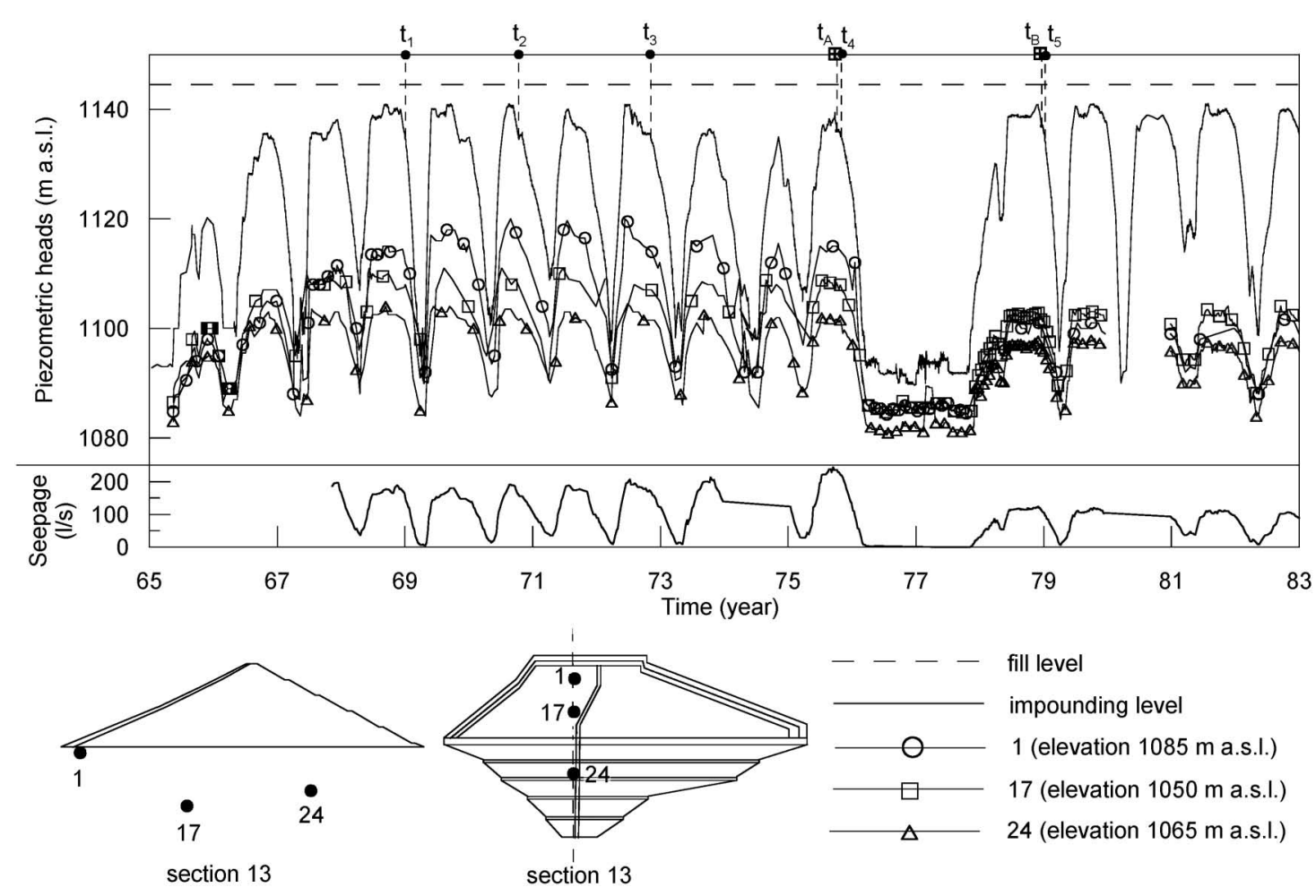

Fig. 14. Zoccolo Dam: impounding levels, piezometric heads at the section 13 and seepage flows measured during the first two decades of the dam lifetime

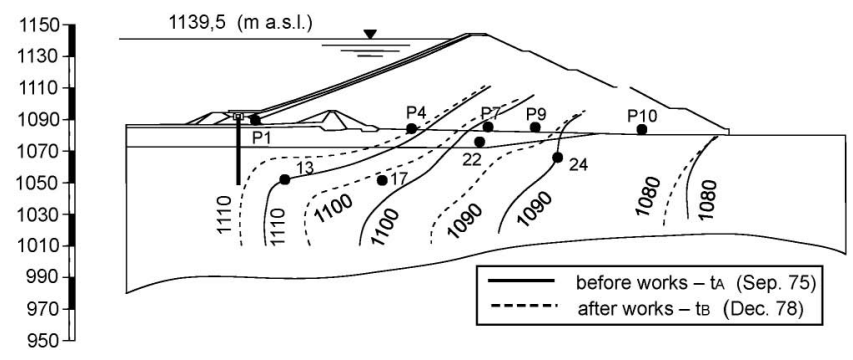

Fig. 15. Zoccolo Dam: piezometric head contours from measurements taken just before and right after the grouting of foundation piles

watertightness problems were essentially located in the left part of the dam.

For this case, piezometric heads worked as an effective indicator of the ongoing problem in the same way as seepage flows, but with the additional potentialities of indicating the zone where the problem took place, and, as occurred for the measurements taken in the transversal gallery, of anticipating the problem itself (the upstream increase of piezometric heads precedes the seepage increase).

In synthesis, the key points making piezometric head measurements effective indicators of watertightness problems in the Zoccolo Dam were the continuously re-equilibrated hydraulic conditions that make the measurement points promptly sensitive to changes in permeability distribution, without any influence of the static conditions on the piezometric head values.

Other factors also concurred in making porewater measurements as valid indicators of the ongoing problem. Fundamental was the circumstance that the watertightness problem determined an alteration of the permeability distribution. Piezometric heads are, in fact, sensitive to changes in the permeability distribution while are unaffected by changes in permeability occurring homogeneously over the entire seepage domain. Fundamental also was the availability of piezometers installed along the seepage paths, which provided the piezometric head distribution.

For the Polverina Dam, Fig. 18(a) adds to the evolution of impounding level and seepage flows that of piezometric heads at the piezometer cells (P17, P18 and P19) of section 3. These cells are located in the lower part of the core and just above the top of the diaphragm, i.e., in the zone where the watertightness deficiency of the dam was argued. Figure 18(b) plots the piezometric head distribution along the same measurement points at ten different times ranging between the construction stages and first operational stages.

During the construction stages (Fig. 18) the dead load soon produced core saturation and, later, development of excess pore water pressure under nearly undrained conditions. Pore water pressure measurements do not arise consistent with what is expected on the basis of simple behavioural models: the embankment geometry, since symmetrical with respect to the core axis, is supposed to induce symmetrical total stress during its construction and, consequently, symmetrical pore water pressure increments with a maximum just in correspondence to the core axis. 

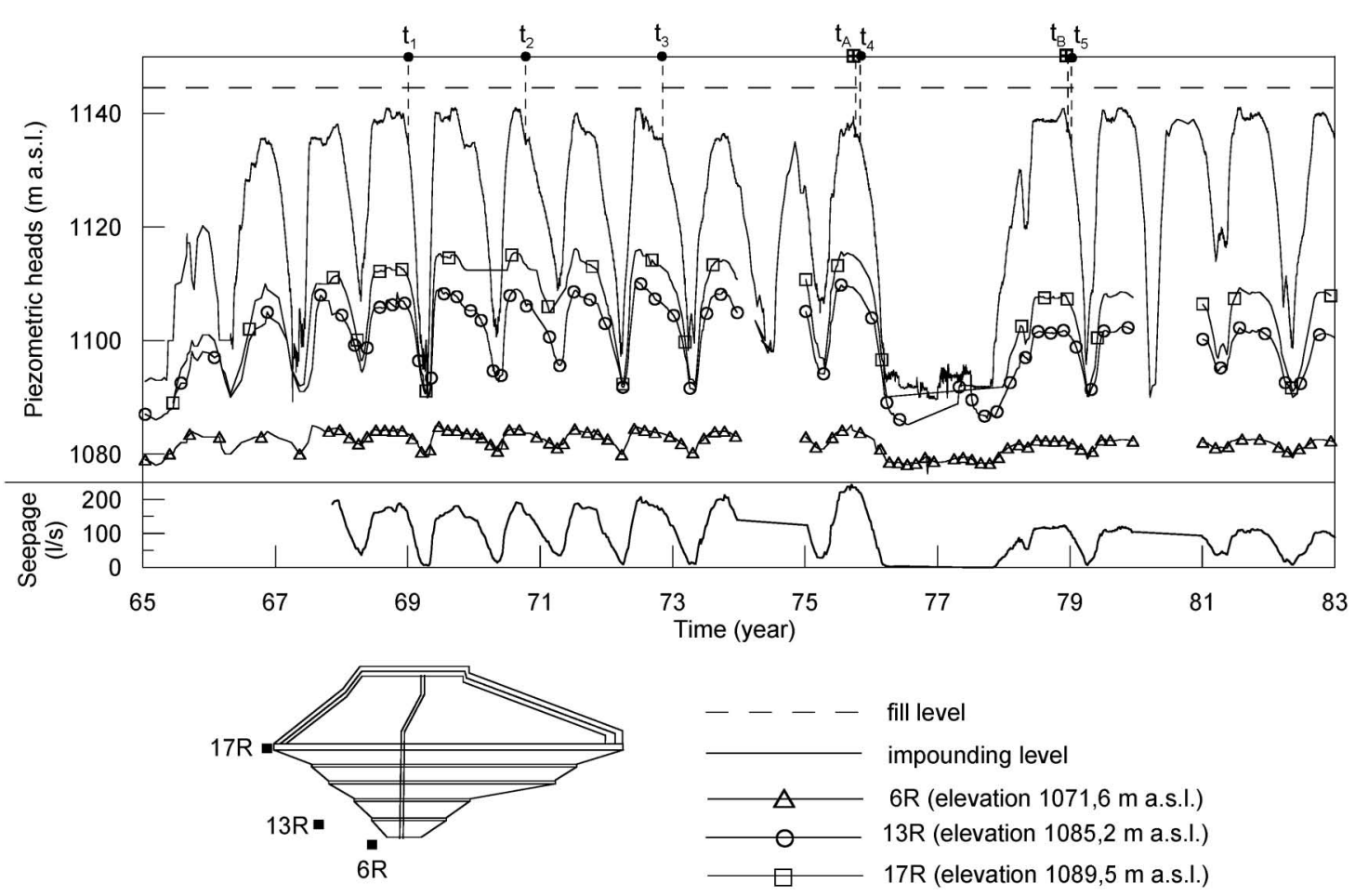

Fig. 16. Zoccolo Dam: impounding levels, piezometric heads in the foundation soils (right bank) and seepage flows measured during the first two decades of the dam lifetime

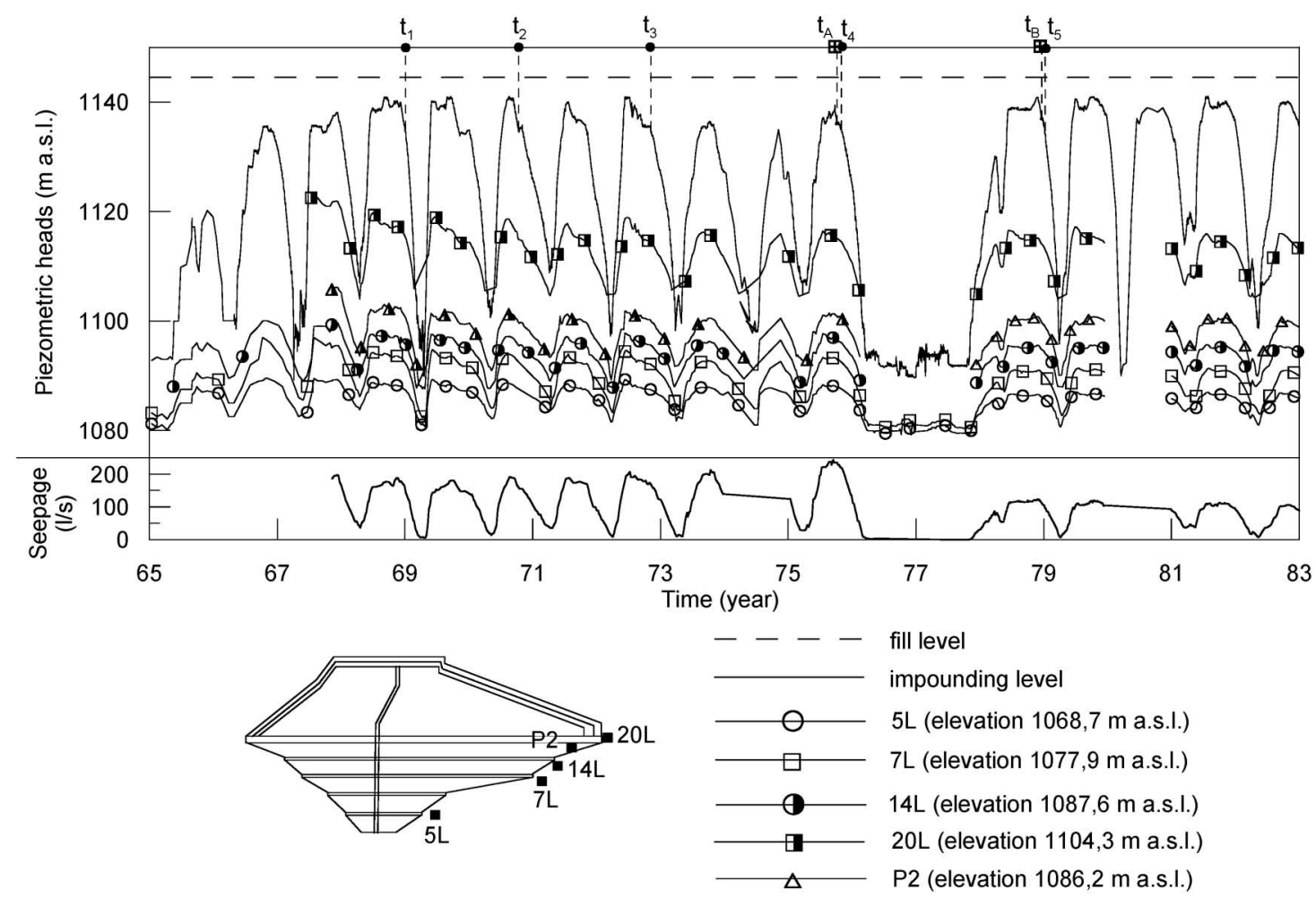

Fig. 17. Zoccolo Dam: impounding levels, piezometric heads in the foundation soils (left bank) and seepage flows measured during the first two decades of the dam lifetime

After construction, the piezometric heads follow a decreasing trend due to core consolidation. When the impounding level goes up during the trial fills (Fig. 18, branch O-A) the time histories of piezometric heads do not show any appreciable change associated with the observed increase in seepage flows and the subsequent stoppage to grout the cut-off wall. Only the piezometer located upstream seems to pick up, even slightly and with 


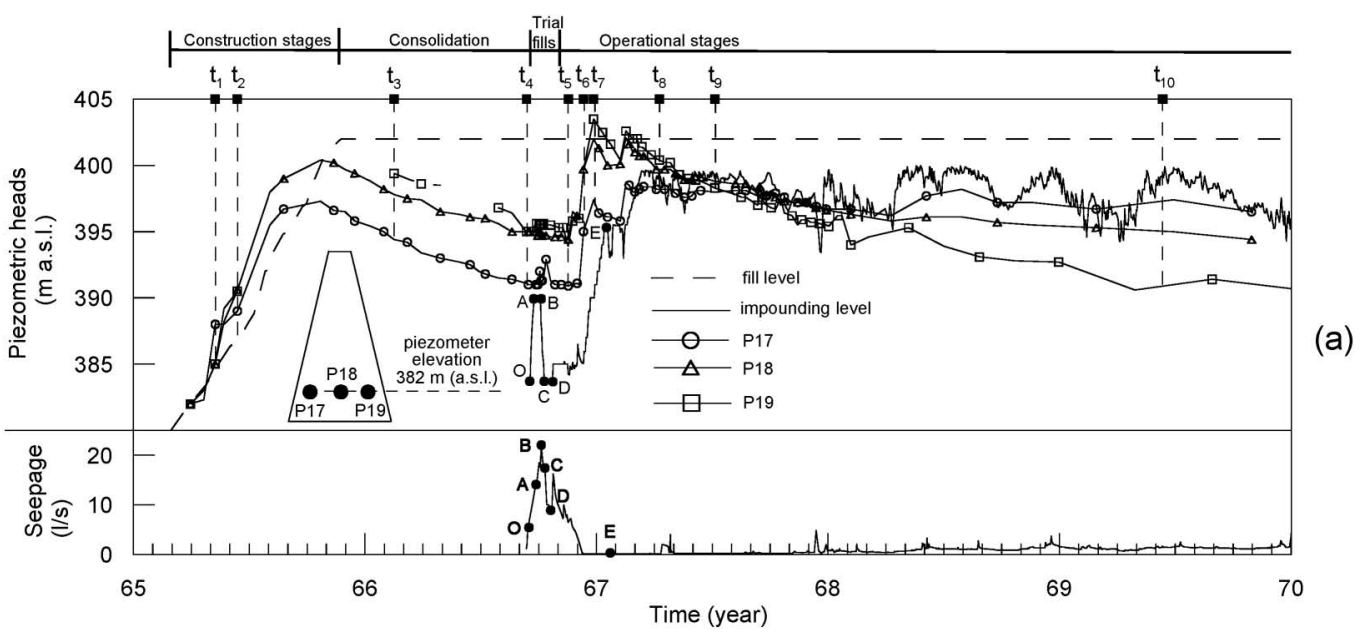

(a)

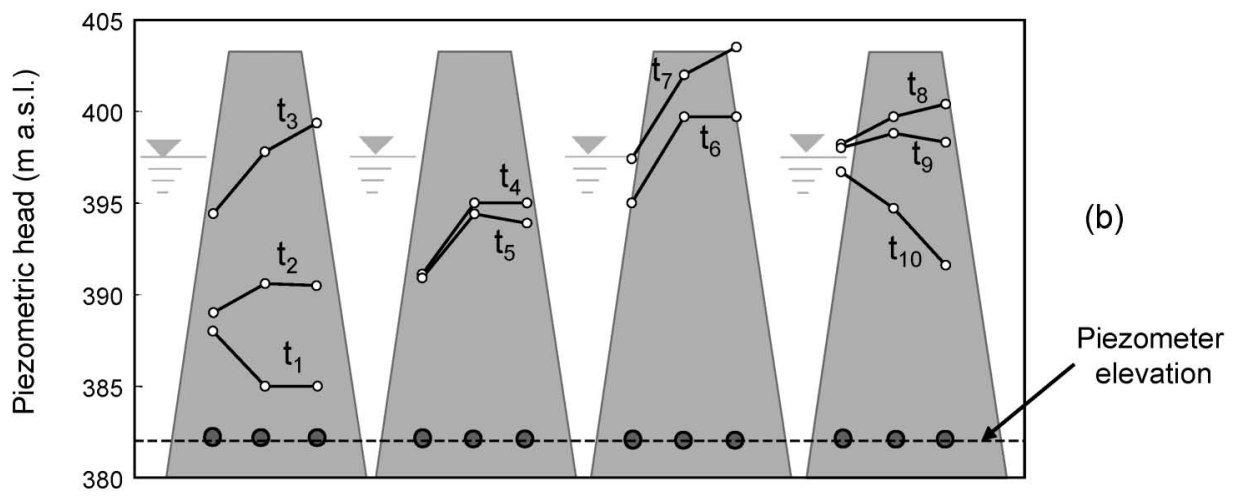

Fig. 18. Polverina Dam: (a) impounding levels, piezometric heads at section 3 and seepage flows measured during construction and up to the beginning of operational stages and (b) isochrones of piezometric heads measured at section 3 during construction and at the beginning of operational stages

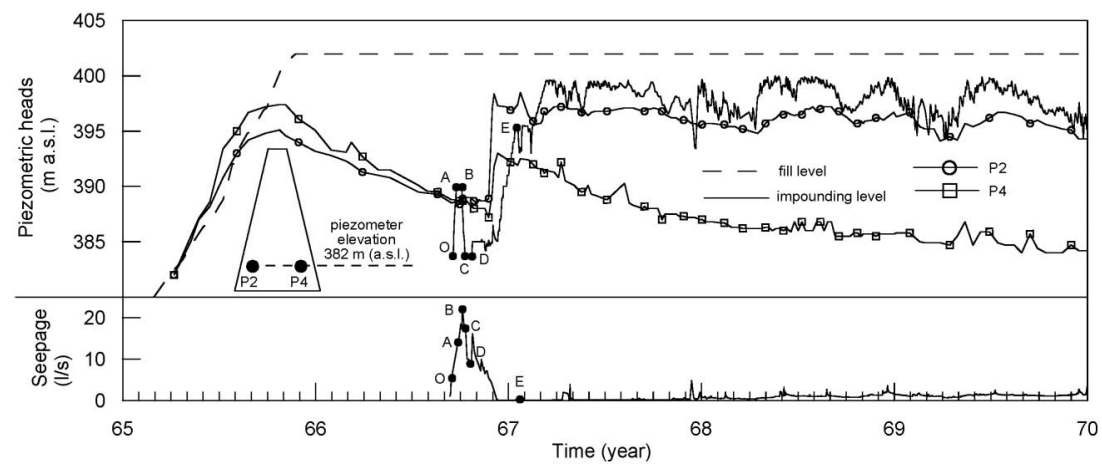

Fig. 19. Polverina Dam: impounding levels, piezometric heads at section 4 and seepage flows measured during construction and up to the beginning of operational stages

some delay, the increase in impounding level. The watertightness problem brought to light by seepage flow measurements cannot be deduced either from time histories (Fig. 18(a)) or from piezometric head distribution (Fig. 18(b), curves $t_{4}$ and $t_{5}$ ).

Even during the trial fills and the first complete reservoir filling, pore water pressure distributions arise inconsistent with the spatial trends expected on the basis of simple behavioural models, since the maximum increments occur at the downstream piezometer rather than at the upstream one. Only some time after the start of the operational stage, the piezometric head distribution shows a decreasing trend from upstream to downstream (Fig. 18(b), curves $t_{10}$ ). This trend is consistent with a seepage process regulated by the reservoir in an almost steady-state condition and indicates to some extent that the detected values are reliable. Measurements taken at section 4 (Fig. 19) can be interpreted referring to the same framework depicted for the measurements of section 3 .

The main reason explaining why for the Polverina Dam piezometric head measurements did not work as indicators of the ongoing hydraulic problem may be found 
in the nearly undrained conditions taking place after a rapid variation of the boundary conditions. During the construction stages and the subsequent start of the trial fills, the low permeability and the high deformability of the core material made pore water pressure associated with nearly undrained conditions and therefore regulated by total stress changes. Total stress changes may assume a spatial distribution which is significantly affected by local and undetectable changes in soil stiffness. Sensitivity to static factors rather than to hydraulic ones implies that changes in permeability distribution, due to the development of fractures or erosion processes, may poorly affect the pore water pressure distribution. Even if change in permeability influences pore water pressure measurements, such influence could not be distinguished by the effects exerted by static conditions.

In synthesis, for the Polverina Dam coupling between soil skeleton and pore water pressure made almost impossible revealing the presence of fracture and erosion processes inside the core. For this case, piezometric heads did not work as effective indicators of the ongoing problem and only seepage flow measurements were good at such a scope.

\section{CONCLUSION}

In this paper water tightness problems that occurred in two Italian earth dams have been described and interpreted, enhancing the role that each monitored quantity plays in detecting the problems at hand, through the most effective measurement representations.

Two cases of watertightness problems, simply detected through inconsistencies between the reservoir levels and the seepage flows over time, were adopted to test to what extent settlement and pore water pressure observations may contribute to interpret or indicate the problems themselves. The main conclusions of the performed study, which may provide a contribution to future geotechnical developments on the interpretation of earth dam monitored quantities, concern the role of pore water pressure measurements, enhancing when and where they result effective in characterizing dam hydraulic behaviour and, as a consequence, in detecting a watertightness problem.

During nearly undrained processes, pore water pressures are strongly regulated by total stress changes. Sensitivity to static factors rather than to hydraulic ones makes pore water pressures poor affected by those changes in permeability distribution, often associated to watertightness problems: spatial changes in stiffness may induce unexpected pore pressure distribution, which may also lead to the wrong belief of unreliable measurements, as it happened, for instance, for the pore water pressures measured in the Polverina Dam core during the construction stages or the trial fills. For this reason, the pore water pressure results insensitive to the presence of fractures and erosion processes and cannot work as effective indicators of hydraulic problems. In nearly undrained conditions, only seepage flow measurements may be adopted to check dam hydraulic behaviour.

Pore water pressures are useful for detecting watertightness problems only when significant re-equilibrium processes take place within the embankment so that they gain sensitivity to change in hydraulic properties, as shown for the case of Zoccolo Dam. Since this sensitivity results much more pronounced as the measurement point is closer and closer to the zone where the change arises, measurements may be very effective also in detecting where the watertightness problem is occurring. The Zoccolo case-study also indicated that pore water pressures, when compared to seepage flows, may have the further potential to detect the problem ahead of time or when seepage flows are undetectable, and moreover to locate it. Different representations (time histories, spatial distributions, contours) may be effective to such a scope.

In this paper the "time-off" during which pore-water pressure measurements, since significantly affected by mechanical factors, are difficult to be interpreted and poorly effective in detecting hydraulic problems, has been discussed with reference to the monitoring data of the early stages of the Polverina Dam life. This "time off", may, however, be quantified through modern analysis tools based on coupled approaches, with regard to all those stages in dam's life which may give rise to undrained processes. Other than during the first impounding stages, the characterization of the "time off', for pore-water pressure measurements may result in practical interest whenever significant and quick oscillations of the reservoir water-table take place or after a strong-motion earthquake inducing significant pore pressure build-up in the dam embankment.

The paper has also enhanced that seepage flow measurements, as expected, represent the main tool through which it is possible to detect water tightness problems. Due to their integral meaning, seepage measurements may be very representative and, therefore, effective at indicating anomalous hydraulic behaviour either if drained or undrained conditions take place in the soils intercepted by the flow paths.

To interpret the hydraulic behaviour of an earth dam, effectiveness of the seepage flow measurements depends, however, on the extension of the zone from which any measurement point collects water. If such an extension is wide, i.e., if water is collected from the entire dam, sensitivity of seepage flows to hydraulic problems is reduced along with the capability in locating the problem itself. In such a case, seepage flows evidence the problem only when the latter is in an advanced state with a significant amount of seeped water, such as for the Zoccolo and Polverina Dam cases.

For both the analysed cases, settlement interpretation resulted very useful to diagnose the observed watertightness deficiency. Displacement measurements, represented through isochrones, resulted valuable at indicating the distortion level in that part of the system where rigid watertightness elements, not suitable to face differential settlements, are present. 


\section{ACKNOWLEDGMENTS}

The Authors wish to thank the Italian National Dam Service for their financial support for this research project and, in particular, engineers Angelica Catalano, Vincenzo Chieppa and Claudia Russo for their help and suggestions throughout.

\section{REFERENCES}

1) Charles, J. A. (1997): Special problems associated with earthfill dams, 19th Congress on Large Dams (General Reporter), CIGB ICOLD, Florence, Italy, 1083-1198.

2) Dounias, G. T., Potts, D. M. and Vaughan, P. R. (1996): Analysis of progressive failure and cracking in old British dams, Geotechnique, 46(4), 621-640.

3) Gould, J. P. and Lacy, H. S. (1993): Seepage control in dam rehabilitation, Geotechnical Practice in Dam Rehabilitation, ASCE Geotechnical Special Publication, 35, 240-255.

4) Jappelli, R. (2003): Le costruzioni geotecniche per le grandi dighe in Italia, Rivista Italiana di Geotecnica (Italian Geotechnical Journal), 37(2), 17-78 (in Italian).

5) Johansen, P. M. and Eikevik (1997): Internal Erosion and Rehabilitation of Jukla Rockfill Dams, 19th Congress on Large Dams,
CIGB ICOLD, Florence, Italy, 245-253.

6) Martin, R. E. (1993): Embankment dam safety, Geotechnical Practice in Dam Rehabilitation, ASCE Geotechnical Special Publication 35, 43-55.

7) Pagano, L., Desideri, A. and Vinale, F. (1998): Interpreting the Settlement Profiles of Earth Dams, Journal of Geotechnical and Geoenvironmental Engineering, ASCE, 124(10), 923-932.

8) Pagano, L., Silvestri, F. and Vinale, F. (2001): A back-analysis of Beliche Dam, Discussion on Géotechnique, 51(4), 377-380.

9) Pagano, L., Sica, S. and Desideri, A. (2006): Representativeness of measurements in the interpretation of earth dam behaviour, Canadian Geotechnical Journal, 43(1), 87-99.

10) Riemer, W., Gavard, M., Soubrier, G. and Turfan, M. (1997): The seepage at the Ataturk fill dam, 19th Congress on Large Dams, CIGB ICOLD, Florence, Italy, 613-633.

11) Sica, S., Pagano, L. and Modaressi, A. (2008): Influence of past loading history on the seismic response of earth dams, Computers and Geotechnics, 35, 61-85.

12) Sherard, J. L. (1986): Hydraulic fracturing in embankment dams, J. Geotech. Engrg., ASCE, 110(10), 905-927.

13) Talbot, J. R. and Deal, C. E. (1993): Rehabilitation of cracked embankment dams, Geotechnical Practice in Dam Rehabilitation, ASCE Geotechnical Special Publication, 35, 267-283.

14) Torbla, I. and Rikartsen, C. (1997): Songa, sudden variation of the leakage in a 35 years old rockfill dam, 19th Congress on Large Dams, CIGB ICOLD, Florence, Italy, 255-267. 